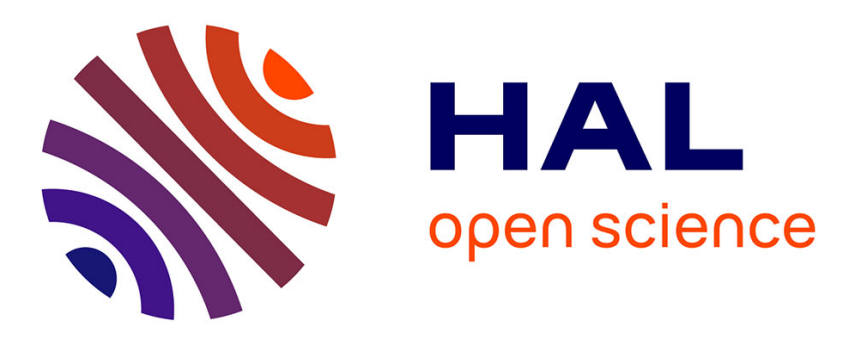

\title{
Experimental investigation of tool wear and its effect on TiSiN-coated ball-end mill geometry in high-speed milling
}

\author{
Rami Belguith, Maher Baili, Saï Lotfi, Mihed Ben Said, Gilles Dessein, \\ Wassila Bouzid
}

\section{To cite this version:}

Rami Belguith, Maher Baili, Saï Lotfi, Mihed Ben Said, Gilles Dessein, et al.. Experimental investigation of tool wear and its effect on TiSiN-coated ball-end mill geometry in high-speed milling. International Journal of Advanced Manufacturing Technology, 2019, 104 (9-12), pp.40634075. 10.1007/s00170-019-04165-4 . hal-02434408

\section{HAL Id: hal-02434408 \\ https://hal.science/hal-02434408}

Submitted on 10 Jan 2020

HAL is a multi-disciplinary open access archive for the deposit and dissemination of scientific research documents, whether they are published or not. The documents may come from teaching and research institutions in France or abroad, or from public or private research centers.
L'archive ouverte pluridisciplinaire HAL, est destinée au dépôt et à la diffusion de documents scientifiques de niveau recherche, publiés ou non, émanant des établissements d'enseignement et de recherche français ou étrangers, des laboratoires publics ou privés. 


\section{OATAO \\ Open Archive Toulouse Archive Ouverte}

\section{Open Archive Toulouse Archive Ouverte}

OATAO is an open access repository that collects the work of Toulouse researchers and makes it freely available over the web where possible

This is an author's version published in: http://oatao.univ-toulouse.fr/25181

Official URL:

https://doi.org/10.1007/s00170-019-04165-4

\section{To cite this version:}

Belguith, Rami and Baili, Maher and Lotfi, Saï and Ben Said, Mihed and Dessein, Gilles and Bouzid, Wassila Experimental investigation of tool wear and its effect on TiSiN-coated ballend mill geometry in high-speed milling. (2019) The International Journal of Advanced Manufacturing Technology, 104 (9-12). 4063-4075. ISSN 0268-3768

Any correspondence concerning this service should be sent to the repository administrator: tech-oatao@listes-diff.inp-toulouse.fr 


\title{
Experimental investigation of tool wear and its effect on TiSiN-coated ball-end mill geometry in high-speed milling
}

\author{
Rami Belguith ${ }^{1,2}$ (D) Maher Baili $^{2} \cdot$ Lotfi Sai $^{1} \cdot$ Mihed Ben Said $^{1} \cdot$ Gilles Dessein $^{2} \cdot$ Wassila Bouzid $^{1}$
}

\begin{abstract}
In this paper, an experimental investigation was carried out in order to identify the tool life of sintered carbide ball-end mill based on spindle speed variation. The used tool is coated with titanium silicon nitride "TiSiN" which is a high-hardened and high heatresistant coat. Experiments were conducted on parallelepiped plane workpieces on AISI 4142 during high-speed milling. Two kinds of tests were realized, the first is a wear experiment using high cutting parameters in order to identify the wear criterion model as a function of the spindle speed. The second one is an accelerated wear experiment to develop an empirical model for the tool life. The research revealed that the tool life and wear criterion value decrease when increasing the spindle speed. It is observed that the wear increases linearly in the normal wear zone. Furthermore, the effect of tool wear on the ball-end mill geometry and the cutting parameters were also investigated. A noticeable variation was found on the effective radius of the tool which affect the tool geometry such as the direction angles of the elementary cutting edge which results in the variation of the cutting parameters. An important effect also of the effective radius variation on the cutting speed was proved.
\end{abstract}

Keywords Ball-end mill $\cdot$ Wear $\cdot$ TiSiN coat $\cdot$ Tool life $\cdot$ Wear criterion value $\cdot$ Tool geometry $\cdot$ High-speed milling

\begin{tabular}{ll}
\multicolumn{2}{l}{ Nomenclature } \\
$f_{z}$ & Feed per tooth (mm/tooth) \\
$N$ & Spindle speed (RPM) \\
$N_{f}$ & Number of flutes \\
$V_{B}$ & Flank wear (mm) \\
$T$ & Tool life (min)
\end{tabular}

Rami Belguith

rami.belguith@gmail.com

Maher Baili

maher.baili@enit.fr

Lotfi Sai

lotfi_sai@yahoo.com

Mihed Ben Said

mihed.bensaid@gmail.com

Gilles Dessein

gilles.dessein@enit.fr

Wassila Bouzid

wassilabouzid@yahoo.fr

1 Unité de Génie de Production Mécanique et Matériaux, ENIS, 3083 Sfax, Tunisia

2 LGP- ENIT, Université de Toulouse, Tarbes, France
$R \quad$ Discretized radius (mm)

$P a \quad$ Discretization plane

$P$ S $\quad$ Edge tangential plane

$P$ n Normal plane

$\gamma_{o}(z) \quad$ Rake angle in the plane $P_{\mathrm{o}}(\mathrm{rad})$

$\lambda_{s}(z, t) \quad$ Cutting edge angle in the plane $P_{\mathrm{S}}$

$i_{0} \quad$ Helix angle $\left(^{\circ}\right)$

$\theta_{V_{B} o}(z, t) \quad$ Offset angle due to flank wear in the plane $P$ o

$\theta_{V_{B} a}(z, t) \quad$ Offset angle due to flank wear in the plane $P \mathrm{a}$

$\psi(\theta, z, t) \quad$ Angular position of each increment (rad)

$t_{n}(\theta, z) \quad$ Uncut chip thickness (mm)

$\psi_{\text {lim }}, \kappa_{\text {lim }} \quad$ Limit angles of the engaged tool/workpiece area (rad)

$a, g \quad$ Wear criterion model constants

$c, d \quad$ Tool life model constants

$r \quad$ Common difference between levels

$z \quad$ The height of discretized disk

$\Delta t \quad$ The milling duration of each surface (min)

$\theta(t) \quad$ Rotational angle $\left(^{\circ}\right)$

ae Radial depth of cut

ap Axial depth of cut

$V_{B} * \quad$ Flank wear criterion value (mm)

$R_{n} \quad$ Nominal radius ( $\mathrm{mm}$ )

$R_{n 0} \quad$ Initial nominal radius (mm) 


$\begin{array}{ll}P r & \text { Reference plane } \\ P \text { o } & \text { Orthogonal plane } \\ \kappa(z, t) & \text { Direction angle of each increment (rad) } \\ \gamma_{a} & \text { Rake manufacturer angle in the plane } P \text { a } \\ \alpha_{a} & \text { Clearance manufacturer angle in the plane } P \text { a } \\ i_{L}(z, t) & \text { Local helix angle }\left(^{\circ}\right) \\ \alpha_{o}(z) & \text { Clearance angle projection in the plane } P \text { o (rad) } \\ \gamma_{n}(z) & \text { Rake angle in the plane } P \text { n (rad) } \\ \varphi(z, t) & \text { Angular position of each increment } \\ & \text { from tooth tangent (rad) } \\ d b(z, t) & \text { Chip width (mm) } \\ \Delta V_{B} & \text { The flank wear measured after the } \\ t & \text { milling of one surface (mm) } \\ k & \text { Time (min) } \\ \Delta z & \text { Wear constant } \\ V f & \text { The height of the elementary disk (mm) }\end{array}$

\section{Introduction}

Tool wear is one of the most important problems when optimizing the cutting process. This unwanted defect decreases the tool performance and causes its replacement. Therefore, this issue has an important economic impact on the machining process [1]. To develop the high-speed machining with a very high precision and efficiency in dry finishing, many types of coatings are used to improve the thermal and mechanical properties of the tool. Furthermore, several researchers have analyzed the wear of coated tools used in machining in order to show the effect of each type of coating on the wear evolution.

Sai et al. [2] proved using an experimental investigation on the AISI 4340 steel in high-speed turning that for coated carbide tools, tool life decreases when increasing the cutting speed where the wear rises notably once the coating layer is removed and the soft substrate wears quickly. They also proved the best behavior of the ceramic cutter with high life for highest speeds. The tool life in this work is defined using a wear criterion model and not as constant because of its dependence on the cutting speed. An empirical model of the tool life was predicted to optimize the achievement of a maximum tool life. Bouzakis et al. [3] have investigated the effect of TiN, TiAlN, and TiSiN properties on the tool wear in the milling process. It was found that $\mathrm{TiSiN}$ has the best coating resistance and fatigue behavior.

Szymon et al. [4] have compared the tool life of sintered carbide coated with TiAlN and cubic boron nitride when machining the X155CrVMo12-1. They predicted a mechanistic cutting force model considering the tool wear. The results showed that the sintered carbide tool had better behavior than the cubic boron nitride for some cutting configurations and had disastrous wear above $\mathrm{Vc}=500 \mathrm{~m} / \mathrm{min}$. Twardowski et al. [5] have investigated the tool wear during milling of hardened steels (55NiCrMoV6 and X153CrMoV12) using sintered carbide and boron nitride tools. The tool life was analyzed based on the variation of cutting speed. Therefore, the tests were divided into three categories where the sintered carbide tool was recommended only for $\mathrm{Vc}<300 \mathrm{~m} / \mathrm{min}$. For $\mathrm{Vc}>500 \mathrm{~m} / \mathrm{min}$, the boron nitride edges have to be used. The intermediate range presents a transition area. They also indicated that for ball-end tools, the rise of the cutting speed to 300 $\mathrm{m} / \mathrm{min}$ leads to the decrease of the tool life with $35 \%$ because of the quick wear. Wang et al. [6] have investigated the effect of two sorts of carbide tools coated with TiSiN and TiAlN. Experiments showed that in high-speed machining of hardened steels, the main wear observed in the initial and stable wear stages was the abrasive wear through the flank wear. Rake face worn, breakage, and chipping appear after peeling of coating because of the diffusion and oxidation. This work compared the behavior of the two coatings. For the TiAlN coating, the wear increases linearly, damage is observed on the tip, and the tool life was $12.8 \mathrm{~m}$. The stable wear was longer for the TiSiN-coated tools, the wear resistance was better than the TiAlN coating, and the tool life was four times longer. Stavropoulos et al. [7] have investigated the limitations of the tool wear prediction in face milling and machining the CGI 450 plates. The principle of the method is to use simultaneously the detection of acceleration and spindle energy current sensor signals. The prediction of the tool wear was defined by experimental results from third-degree regression models and design recognition systems. The wear experiments were made based on the analysis of cutting force variations, the spindle current, and the dynamic behavior of the machine tool. It was shown that this predictability is affected by the mean signal energy, acquired from vibration acceleration signals. Yuan et al. [8] found that TiSiN coating had the best hardness of $34.9 \mathrm{GPa}$ and the highest Young's modulus with a value of $453.5 \mathrm{GPa}$. For high-speed milling of hardened steels, the wear is manifested from peeling, adhesive, diffusion, and oxidation. In a recent paper, Okokpujie et al. [9] have developed an empirical model of high-speed steel tool wear machining the 1061 aluminum alloy. The tool wear was investigated as a function of the cutting speed, feed rate, and radial depth of cut using a scanning electron microscope to measure the tool wear. On the other hand, many works have presented the importance of the TiSiN coating on the mechanical and thermal behavior of the tool. Chang et al. [10] found that the hardness of the TiSiN coating (from 32 to $38 \mathrm{GPa}$ ) is higher than that of TiAlN (29 GPa). The adding of the TiSiN layer coating improves mechanical, wear, and corrosion properties. Cheng et al. [11] have also demonstrated that for TiSiN coating, the increase of Si fraction allows the rise of the hardness, Young's modulus, and the friction coefficient. Weicheng et al. [12] have indicated that the TiSiN coating which contains the TiN with the atom "Si" had a hardness of $3550 \mathrm{HV}$ 
and a maximal working temperature of $1300{ }^{\circ} \mathrm{C}$. These characteristics promote the use of this coating for dry high-speed machining. Ning et al. [13] have predicted a mechanistic force model for ball-end milling including tool wear. The cutting force is calculated by the summation of the forces from the rake face, cutting edge, and flank face. The flank force is defined according to the flank wear. Ben Said et al. [14] have developed an analytical model of cutting forces based on the thermomechanical approach in oblique cutting. The tool geometry and the cutting parameters are defined according to the flank wear in ball-end milling. The ball-end tool geometry used in this study is also the same as that used by Sai et al. [15], developing an analytical model of the cutter-workpiece engagement (CWE) region and the cutting parameters in three- and five-axis ball-end milling. Ji et al. [15] have developed a geometry model to cross-section parameters of chamfered cutting edge of a ball-end mill machining a solid carbide.

The purpose of this paper is to present an experimental investigation to identify the ball-end mill coated with TiSiN wear behavior. Therefore, this work contains a wear experiment using hard constant cutting parameters in order to identify the wear criterion model of the used tool as a function of the spindle speed. The second objective is to predict an empirical model for the tool life using the accelerated wear experiment with different cutting parameters. These models are used to illustrate the effect of the flank wear on the tool geometry, mainly the decrease of the effective tool radius according to time. This diminution induces the decrease of the cutting speed and modifies the cutting geometry.

\section{Worn tool geometry modeling}

The worn tool geometry is presented according to the reference, discretized, and edge tangential planes (Fig. 1). The initial tool geometry parameters are defined for $t=0$ and the initial radius is $R_{n}(z, t=0)=R_{n 0}$. These parameters are considered variable as a function of the tool wear in time. The length of the linear infinitesimal cutting edge projection in the reference plane $\operatorname{Pr}$ is defined by the distance $P_{\mathrm{i}} P_{\mathrm{i}+1}$ which is supposedly linear because of its law value (Fig. 1a). The worn cutting edge is given in the tangent plane $P$ s inclined by the angle $\lambda_{s}(z, t)$ where the elementary cutting edge is defined by the distance $P_{\mathrm{i}} P^{\prime}{ }_{\mathrm{i}+1}$ (Fig. 1c). The point $P_{\mathrm{i}}$ from the cutting edge is positioned in the plane of discretization $P$ a as shown in the (Fig. 1b).

The tool flank wear $V_{B}(t)$ has an important effect on the tool geometry parameters. The following relation of the flank wear has a linear behavior, so it is available only before the wear criterion value is reached:

$0 \leq V_{B} \leq V_{B}^{*} \Rightarrow V_{B}(t)=k t=\frac{V_{B} *(t)}{T} t$
$V_{B^{*}}$ and $T$ represent respectively the wear criterion value and the tool life. They are presented by the following equations and will be identified experimentally in the next section:

$$
\begin{aligned}
& T=c N^{d}, \quad V_{B} *=a N^{g} \\
& V_{B}(t)=\frac{a}{c} N^{g-d} t
\end{aligned}
$$

The effective cutting speed could be calculated from the worn tool as a function of the effective diameter affected by the flank wear:

$N=\frac{1000 V_{c_{\text {_efff }}}(z, t)}{\pi D_{\text {eff }}(z, t)} \quad$ with $\quad D_{\text {eff }}(z, t)=2 R(z, t)$

During machining, the effective radius $R(z, t)$ and the effective cutting speed decrease according to the tool flank wear, where the spindle speed $N$ is always constant.

\subsection{Effect of the flank wear on the tool radius}

The flank wear $V B(t)$ of the ball-end tool changes the nominal radius from the initial state $R_{n 0}$ to $R_{n}(z, t)$, in the reference plane $\operatorname{Pr}$ (Fig. 1) and in the orthogonal plane Po (Fig. 2). The position of the cutting edge is modified due to flank wear. It is shifted from its initial position $P_{\mathrm{i}}$ to the new position $P^{\prime \prime}{ }_{\mathrm{i}}$ in the orthogonal plane $P$ o and to $P^{\prime}{ }_{\mathrm{i}}$ in the normal plane $P$ n.

The nominal radius $R_{n}(z, t)$ of the worn tool is given by:

$R_{n}(z, t)=\frac{R_{n 0} \cos \left(\lambda_{s}(z, t=0)\right)-V_{B}(t) \tan \left(\alpha_{o}(z)\right)}{\cos \left(\lambda_{s}(z, t=0)\right) \cos \left(\theta_{V_{B} o}(z, t)\right)}$

$\theta_{V_{B} o}(z, t)$ is the offset angle due to flank wear in the plane $P \mathrm{O}$ and is calculated from Fig. 2:

$P_{i}^{\prime \prime} A_{3 o}=P_{i} A_{3 o} \tan \left(\gamma_{o}(z)\right)=\left(R_{n 0}-P_{i} A_{3 o}\right) \tan \left(\theta_{V_{B} o}(z, t)\right)$

$P_{i} A_{3 o}=A_{2 o} A_{1 o}=\frac{V_{B}(t) \tan \left(\alpha_{o}(z)\right)}{\cos \left(\lambda_{s}(z, t=0)\right)}$

$\tan \left(\gamma_{o}(z)\right)=\tan \left(\gamma_{a}\right) \sin (\kappa(z, t=0))$

$\tan \left(\theta_{V_{B} o}(z, t)\right)=\frac{V_{B}(t) \tan \left(\alpha_{o}(z)\right) \tan \left(\gamma_{a}\right) \sin (\kappa(z, t=0))}{R_{n 0} \cos \left(\lambda_{s}(z, t=0)\right)-V_{B}(t) \tan \left(\alpha_{o}(z)\right)}(9)$

$\alpha_{o}(z)$ is the clearance angle calculated from the angle $\alpha_{a}$ given by the constructor as follows:

$\tan \left(\alpha_{o}(z)\right)=\frac{\tan \left(\alpha_{a}\right)}{\sin (\kappa(z, t=0))}$

The flank wear $V_{B}(t)$ causes also the variation of the discretized effective radius of the tool $R(z, t)$ in the plane $P$ a (Fig. 1a). This radius is given by:

$R(z, t)=\sqrt{R_{n}(z, t)^{2}-\left(R_{n 0}-z\right)^{2}}$ 
Fig. 1 Tool geometry. a Reference plane view Pr. b Discretized plane view $P$ a. c Edge tangential plane view $P$ s

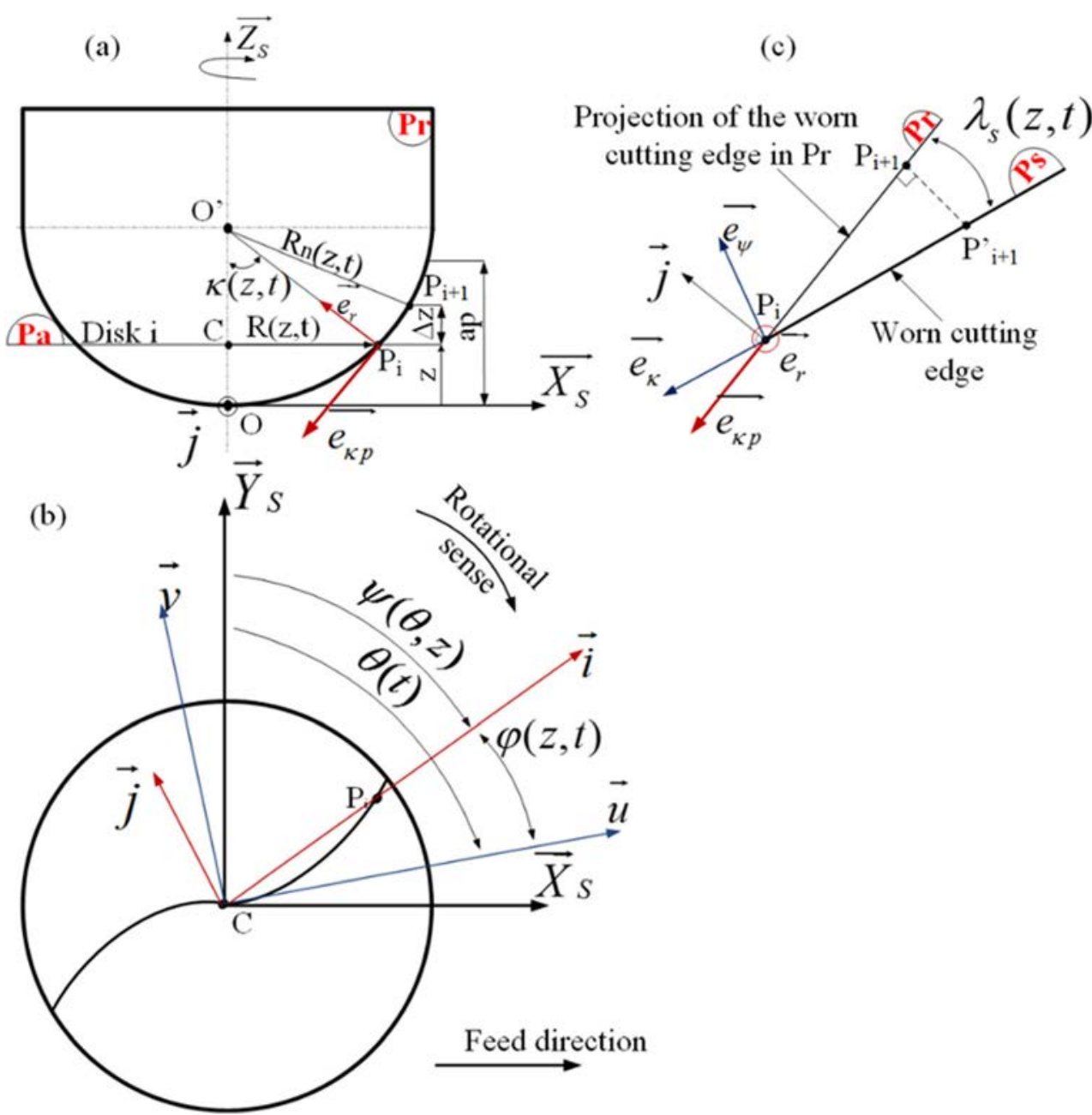
by:

$$
\tan \left(i_{L}(z, t)\right)=\frac{R(z, t)}{R_{n 0}} \tan \left(i_{0}\right)+\frac{R(z, t) \theta_{V_{B} a}(z, t)}{\Delta z}
$$

$\tan \left(\lambda_{s}(z, t)\right)=\tan \left(i_{L}(z, t)\right) \sin (\kappa(z, t))$

The local helix angle $i_{L}(z, t)$ (Fig. 3) and direction angle of each increment $\kappa(z, t)$ in the plane $(P r)$ are given by these equations:

$$
\cos (\kappa(z, t))=\frac{R_{n 0}-z}{R_{n}(z, t)}
$$

Fig. 2 Effect of the flank wear. a

Normal plane projection $P$ n. b

Orthogonal plane projection $P \mathrm{o}$ (a)

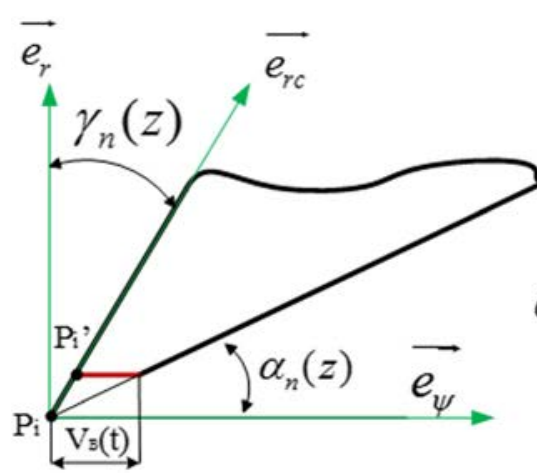

(b)

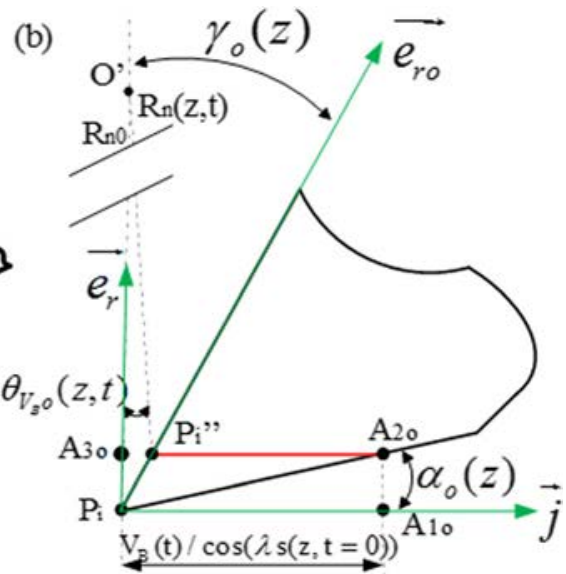




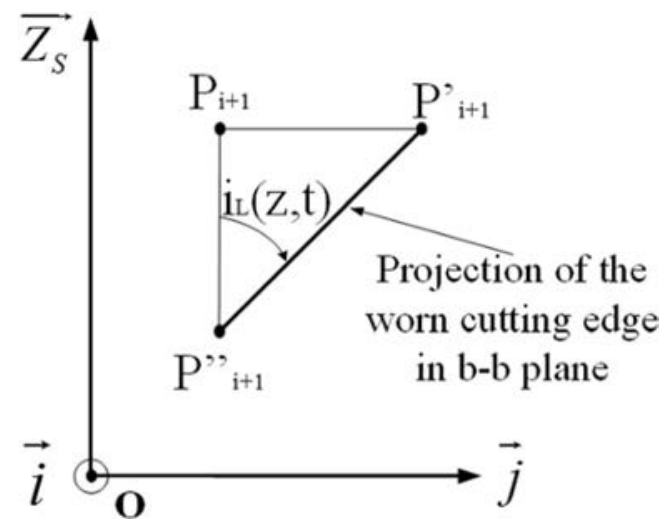

Fig. 3 The local helix angle of the worn tool

\subsection{Effect of the flank wear on the cutting edge angular position}

The position of the cutting edge in the plane $P$ a is defined using a rotated vector $(\vec{u}, \vec{v})$ by the angle $\theta(t)$ according to $\overrightarrow{Y_{S}}$ and $(\vec{i}, \vec{j})$ linked to the point $P_{\mathrm{i}}$ (Fig. 4).

The initial position $P_{\mathrm{i}}$ shifts also in the plane $P$ a to the new position $P^{\prime \prime \prime}{ }_{\mathrm{i}}$.

The angular position of each increment for $Y \mathrm{~s} \psi(\theta, z, t)$ of the point $P_{\mathrm{i}}$ in the cutting edge is defined as follows:

$$
\begin{aligned}
& \psi(\theta, z, t)=\theta(t)+(j-1)\left(\frac{2 \pi}{N_{f}}\right)-\varphi(z, t) \\
& \varphi(z, t)=\varphi(z, t=0)+\theta_{V_{B} a}(z, t) \\
& \varphi(z, t=0)=\frac{z \tan \left(i_{0}\right)}{R_{n 0}}
\end{aligned}
$$

$\varphi(z, t)$ and $\theta_{V_{B} a}(z, t)$ represent respectively the angular position of each increment from tooth tangent of the worn cutting

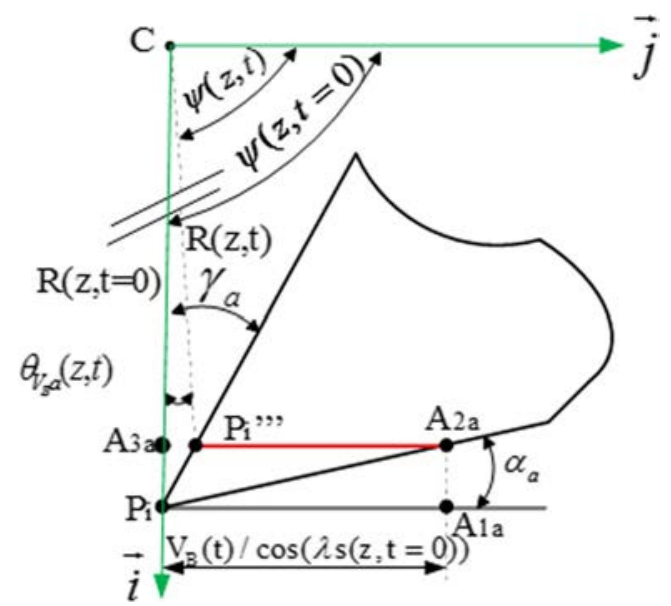

Fig. 4 Effect of the flank wear on the tool geometry in discretization plane $P$ a edge and the offset angle due to the flank wear in the plane $P \mathrm{a}$. $\theta_{V_{B} a}(z, t)$ is defined by this relation:

$$
\tan \left(\theta_{V_{B} a}(z, t)\right)=\frac{V_{B}(t) \tan \left(\alpha_{a}\right) \tan \left(\gamma_{a}\right)}{R(z, t=0) \cos \left(\lambda_{s}(z, t=0)\right)-V_{B}(t) \tan \left(\alpha_{a}\right)}
$$

\subsection{Cutting parameters for worn tool}

The uncut chip thickness of the worn tool can be written as follows (Fig. 5):

$$
t_{n}(z, t)=f_{z} \sin (\psi(z, t)) \sin (\kappa(z, t)) \text { if }\left\{\begin{array}{l}
0 \leq \kappa \leq \kappa_{\lim }(t) \\
0 \leq \psi \leq \psi_{\lim }(t)
\end{array} \text { elset }_{n}(\theta, z)=0\right.
$$

The limit angles are calculated using these equations (Fig. $6)$ :

$$
\begin{aligned}
& \kappa_{\lim }(t)=\cos ^{-1}\left(\frac{R_{n 0}-a p}{R_{n}(z=a p, t)}\right) \\
& \psi_{\lim }(t)=\cos ^{-1}\left(\frac{R(z=a p, t)-a e}{R(z=a p, t)}\right)
\end{aligned}
$$

The chip width is calculated for a worn tool as follows (Fig. $5 b)$ :

$d b(z, t)=\frac{\Delta z}{\sin (\kappa(z, t))}$

\section{Experimental setup}

In this section, the experimental setup is presented through the used machine-tool-workpiece and the measuring means.

Different experiments were carried out on three axis high-speed milling center Huron KX10. The used tools are sintered carbide ball-end mills with two teeth commercialized by Kendu. These tools are used for dry finish milling in highspeed machining. The characteristics are presented in Table 1 .

The workpiece material is the AISI 4142 hardened steel. The workpiece (Fig. 7) was prepared to a parallelepiped form (length $=80 \mathrm{~mm}$, width $=42 \mathrm{~mm}$, height $=10 \mathrm{~mm}$ ). The machining strategy used is one way, ensuring the acceleration and deceleration outside of the milled surfaces. A set of four experiments will be conducted for this purpose. Two experiments (experiment 1 and experiment 2) were conducted in order to define the flank wear criterion model for the used tool, and two experiments (experiment 3 and experiment 4) were carried out using the accelerated wear method to define the Taylorian tool life law.

The first experimental setup was conducted with two values of spindle speed and a feed per tooth $f z=0.1 \mathrm{~mm} /$ tooth . The axial and radial depths of cut were fixed respectively to $a p$ $=1 \mathrm{~mm}$ and $a e=1 \mathrm{~mm}$. 
Fig. 5 Cutting geometry. a Reference plane view. b Detail K. c Discretized plane view (a)

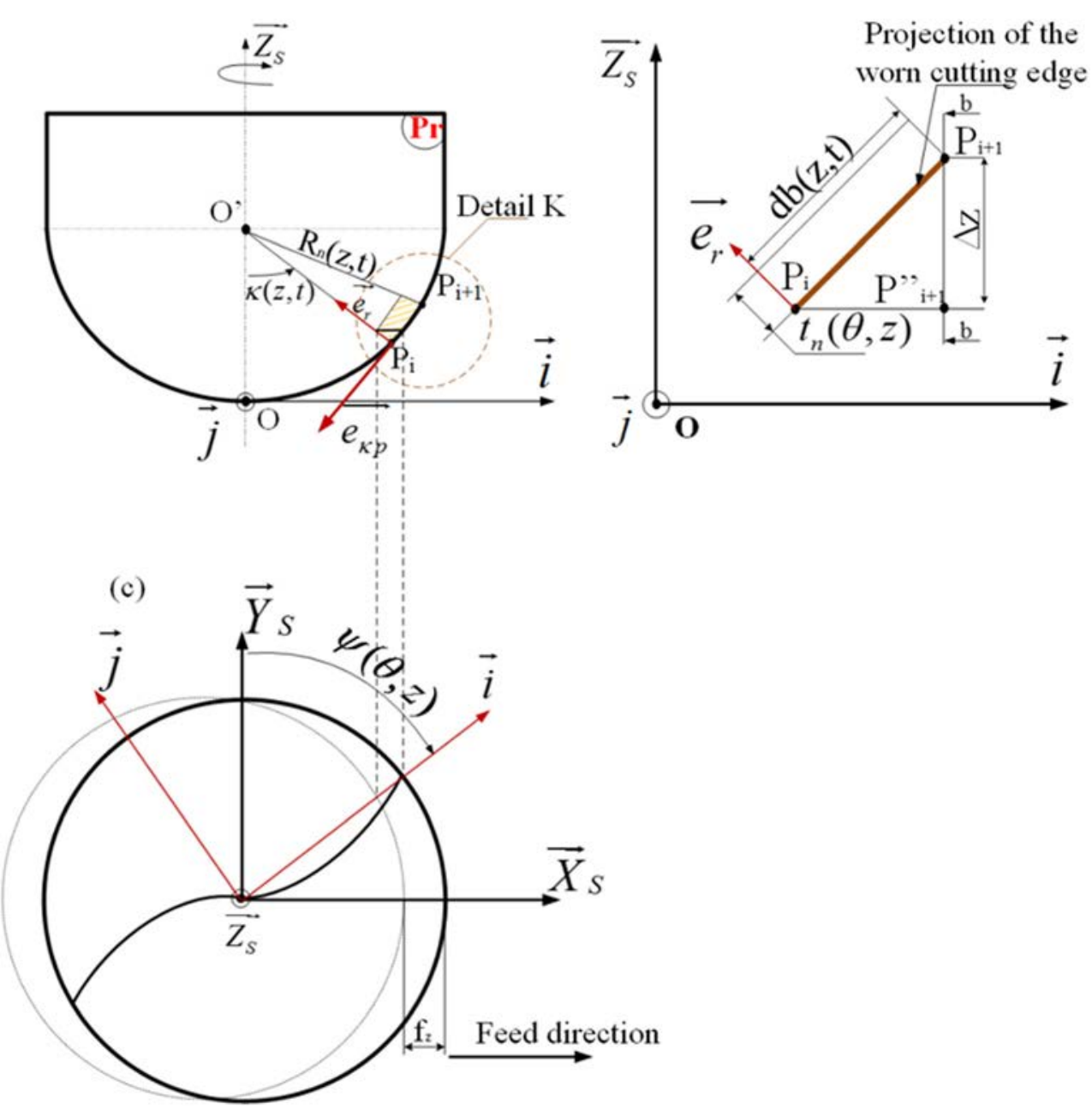

The wear criterion value is taken generally as a constant $V_{B}{ }^{*}=0.3 \mathrm{~mm}$ and, in this work, in high-speed milling, the wear criterion targeted changes according to the cutting parameters, especially the spindle speed. The wear criterion

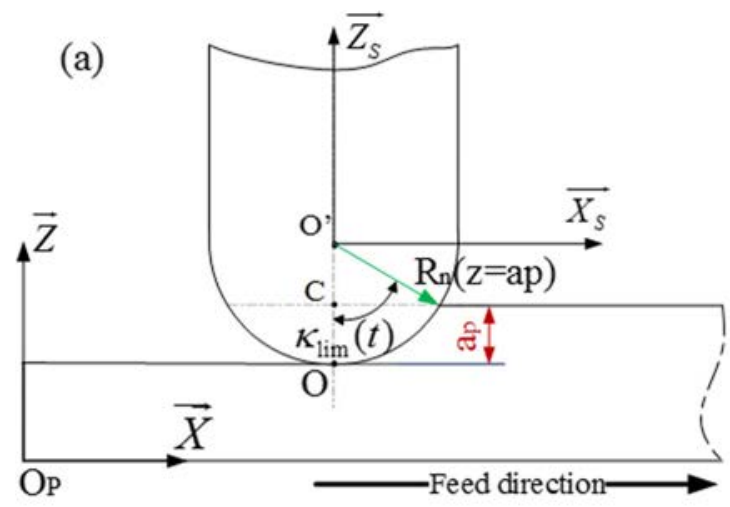

(b)

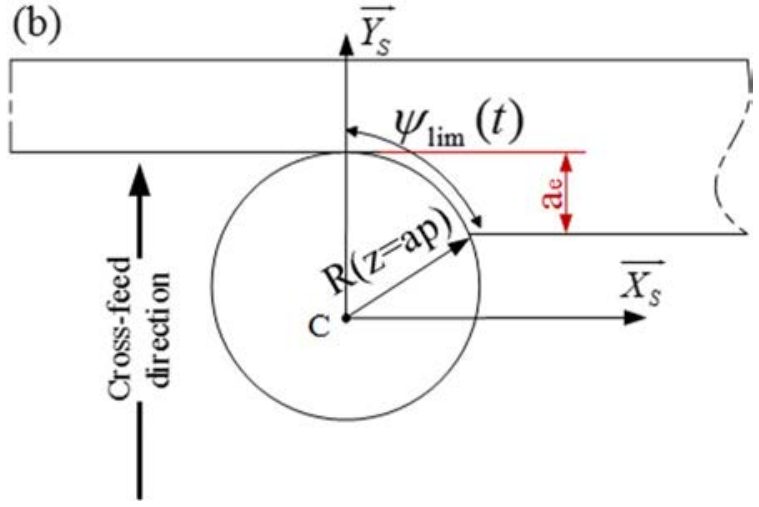

Fig. 6 Tool-workpiece engagement area. a Reference plane view. b Discretized plane view 
Table 1 Tool characteristics

\begin{tabular}{llllll}
\hline Kendu designation & Coating & $R_{n 0}$ & $i_{0}$ & $\gamma_{\mathrm{a}}$ & $\alpha_{\mathrm{a}}$ \\
\hline 3902.52 & TiSiN & $5 \mathrm{~mm}$ & $30^{\circ}$ & $20^{\circ}$ & $12.5^{\circ}$ \\
\hline
\end{tabular}

empirical model was defined in this study through two experiments. Each of them was realized using ball-end mills machining 16 surfaces with a total length of $64 \mathrm{~m}$ and a total time $t_{1}=13.328 \mathrm{~min}$ for experiment 1 and $t_{2}=11.312 \mathrm{~min}$ for experiment 2 (Table 2).

The second experimental setup was carried out to predict an empirical Taylorian wear model for the tool life using the accelerated wear method. These experiments were conducted with two ball-end mills under these parameters: the feed per tooth $f z=0.1 \mathrm{~mm} /$ tooth, $a p=a e=1 \mathrm{~mm}$. The workpiece was divided into four levels; each level contains two surfaces (Fig. $8 \mathrm{~b})$. The difference in the two experiments is that the machining parameters increase in the same workpiece, passing from a level to another with a common difference between levels $r=$ 1.15 (Table 3). The total time of milling is $t_{3}=7.2 \mathrm{~min}$ for experiment 3 and $t_{4}=5.816 \mathrm{~min}$ for experiment 4 by summing the machining time of each test $\Delta t$.

The tool flank wear was measured by using a polarized portable digital microscope Dino-Lite AM7013MZT equipped with a precise orientation support (Fig. 8a). The image processing the measurements was taken using the software DinoCapture 2.0 associated with the used microscope.

\section{Results and discussions}

\subsection{Wear criterion experiments}

The tool wear evolution was measured for experiments 1 and 2. The mean flank wear was measured in zone B away from the tool engagement ends. This wear will be considered as a
Table 2 Machining parameters for experiments 1 and 2

\begin{tabular}{llll}
\hline & Spindle speed & Feed rate & $\Delta t(1$ surface $)$ \\
\hline Experiment 1 & $20,165.4 \mathrm{rpm}$ & $4033 \mathrm{~mm} / \mathrm{min}$ & $0.833 \mathrm{~min}$ \\
Experiment 2 & $23,750.4 \mathrm{rpm}$ & $4750 \mathrm{~mm} / \mathrm{min}$ & $0.707 \mathrm{~min}$ \\
\hline
\end{tabular}

constant along the immersed cutting edge in the workpiece. The used tools had an initial wear for each of them with $V_{B}=$ $0.073 \mathrm{~mm}$ for the tool used for the first experiment and $V_{B}=$ $0.093 \mathrm{~mm}$ for the second experiment.

In the wear criterion tests, 12 values were measured during $13.328 \mathrm{~min}$ for the first experiment and $11.312 \mathrm{~min}$ for the second experiment. The tool wear criterion model is defined based on the spindle speed variation.

In high-speed milling, the input of the machine program is the spindle speed where the effective cutting speed could be determined using the tool diameter. Knowing that this diameter is affected by the wear during machining, we choose to present the wear criterion of the ball-end mill coated with TiSiN as a function of the spindle speed. The observed wear criterion values of the first and second experiments are respectively $V_{B 1} *=0.29 \mathrm{~mm}$ and $V_{B 2} *=0.267 \mathrm{~mm}$, taking into account the initial flank wear for each tool. They were identified clearly from the wear evolution where we presented the tool wear measured as a function of time by subtracting the initial wear of each tool (Fig. 9).

The wear criterion model of the ball-end mill coated with TiSiN is defined as a function of the spindle speed as follows:

$V_{B} *=a N^{g}$

$a$ and $g$ are two constants defined from the spindle speeds and the wear criterion.

This relation defining the evolution of the wear criterion value of the used tool is:

$V_{B} *=40.866 N^{-0.499}$
Fig. 7 a Tool holder setup. b Workpiece

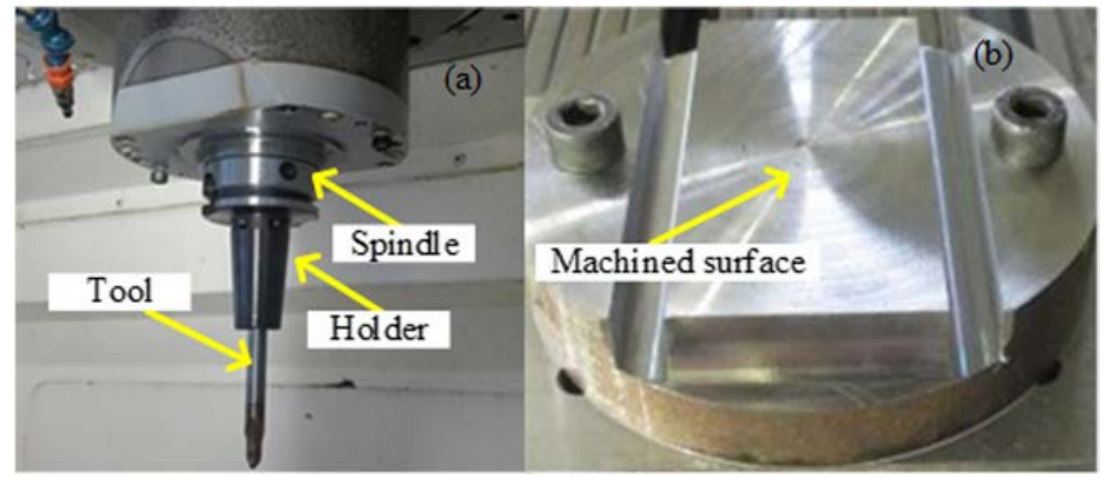


Fig. 8 a Dino-lite camera. b Kistler dynamometer

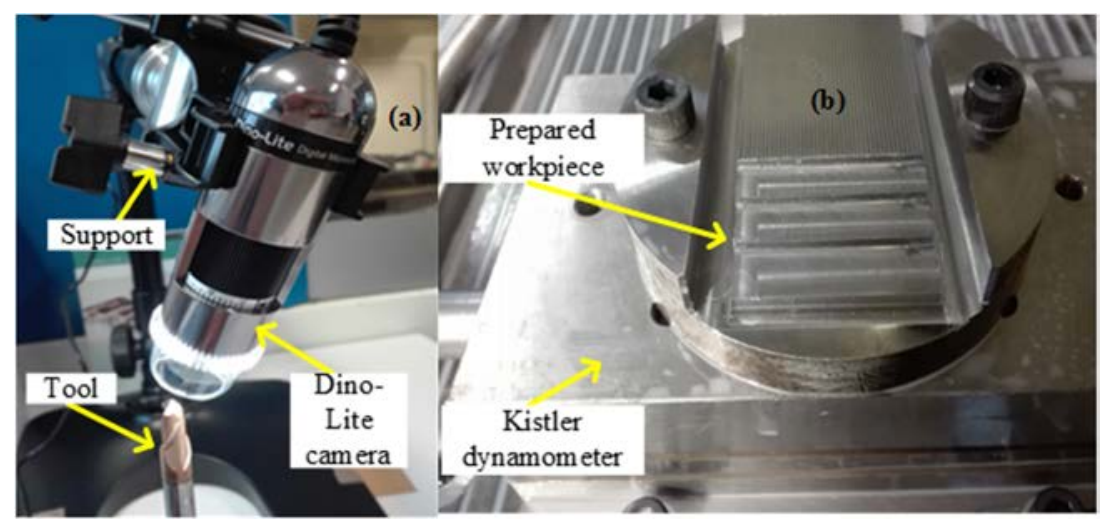

The wear criterion value decreases when increasing the spindle speed. In high-speed machining, the tool wear criterion could not have a constant value and have a very sensitive behavior according to the spindle speed.

\subsection{Accelerated wear experiments}

The definition of the Taylorian tool life model using the accelerated wear method needs only two values of $V_{B}$ after the workpiece machining with the defined configurations (Table 3). The accumulated tool wear of experiment 3 is $V_{B 3}$ $=0.103 \mathrm{~mm}$ and that of experiment 4 is $V_{B 4}=0.135 \mathrm{~mm}$.

The tool wear of the accelerated wear experiments 3 and 4 was measured in the end of the four levels in each workpiece. Using the same reasoning of the tool wear criterion model, we defined the tool life model of the ball-end mill coated with TiSiN as a function of the spindle speed. The effective cutting speed will be calculated later from the real diameter affected by the wear.

The Taylorian tool life model is predicted from the experimental accelerated wear test data and considers the variability of the wear criterion as follows:

- The Taylorian tool life form is defined by:

$T=c N^{d}$

Table 3 Machining parameters of experiments 3 and 4

\begin{tabular}{|c|c|c|c|c|c|}
\hline & \multicolumn{2}{|c|}{ Experiment 3} & & \multicolumn{2}{|c|}{ Experiment 4} \\
\hline & \multicolumn{2}{|c|}{$\Delta \mathrm{t}_{3}=1.8 \mathrm{~min}$} & & \multicolumn{2}{|c|}{$\Delta t_{4}=1.454 \mathrm{~min}$} \\
\hline & $N(\mathrm{rpm})$ & $V f(\mathrm{~mm} / \mathrm{min})$ & & $N(\mathrm{rpm})$ & $V f(\mathrm{~mm} / \mathrm{min})$ \\
\hline Test 1 & $12,738.85$ & 2547.77 & Test 1 & $15,764.33$ & 3152.86 \\
\hline Test 2 & $14,649.68$ & 292.93 & Test 2 & $18,128.98$ & 3625.79 \\
\hline Test 3 & $16,847.13$ & 3369.42 & Test 3 & $20,848.32$ & 4169.66 \\
\hline Test 4 & $19,374.2$ & 3874.84 & Test 4 & $23,975.57$ & 4795.11 \\
\hline
\end{tabular}

- Determination of $c$ and $d$ :

Knowing that the flank wear evolves linearly as a function the time, it is presented as follows:

$V_{B}=K t$

Therefore, the tool wear criterion is defined by:

$V_{B} *=K T \Leftrightarrow K=\frac{V_{B} *}{c N^{d}}$

$V_{B}=\frac{V_{B} *}{c N^{d}} t \quad$ and $\quad V_{B} *=a N^{g}$

The tool wear criterion value is considered variable for experiments 3 and 4 according to the spindle speed. The tool wear equations for the four levels of the two experiments are:

$$
\begin{aligned}
& \Delta V_{B 31}=\frac{a\left(N_{31}\right)^{g}}{c\left(N_{31}\right)^{d}} \Delta t_{3} ; \Delta V_{B 32}=\frac{a\left(r N_{31}\right)^{g}}{c\left(r N_{31}\right)^{d}} \Delta t_{3} \\
& \Delta V_{B 33}=\frac{a\left(r^{2} N_{31}\right)^{g}}{c\left(r^{2} N_{31}\right)^{d}} \Delta t_{3} ; \Delta V_{B 34}=\frac{a\left(r^{3} N_{31}\right)^{g}}{c\left(r^{3} N_{31}\right)^{d}} \Delta t_{3} \\
& V_{B 3}=\Delta V_{B 31}+\Delta V_{B 32}+\Delta V_{B 33}+\Delta V_{B 34} \\
& =\frac{a \Delta t_{3} N_{31}^{g-d}}{c}\left(1+r^{g-d}+r^{2(g-d)}+r^{3(g-d)}\right)
\end{aligned}
$$

Using the same approach for experiment 4:

$$
\begin{aligned}
& V_{B 4}=\Delta V_{B 41}+\Delta V_{B 42}+\Delta V_{B 43}+\Delta V_{B 44} \\
& =\frac{a \Delta t_{4} N_{41}^{g-d}}{c}\left(1+r^{g-d}+r^{2(g-d)}+r^{3(g-d)}\right) \\
& \Rightarrow \frac{V_{B 3}}{V_{B 4}}=\frac{\Delta t_{3} N_{31}^{g-d}}{\Delta t_{4} N_{41}^{g-d}}=\frac{\Delta t_{3}}{\Delta t_{4}}\left(\frac{N_{31}}{N_{41}}\right)^{g-d}
\end{aligned}
$$

The first constant $d$ is given by:

$$
d=g-\frac{\ln \left(\frac{\Delta t_{4} V_{B 3}}{\Delta t_{3} V_{B 4}}\right)}{\ln \left(\frac{N_{31}}{N_{41}}\right)}=-2.77
$$


Fig. 9 Flank wear evolution with time $(f z=0.1 \mathrm{~mm} /$ tooth,$a p=a e=$ $\left.1 \mathrm{~mm}, R_{n 0}=5 \mathrm{~mm}\right)$

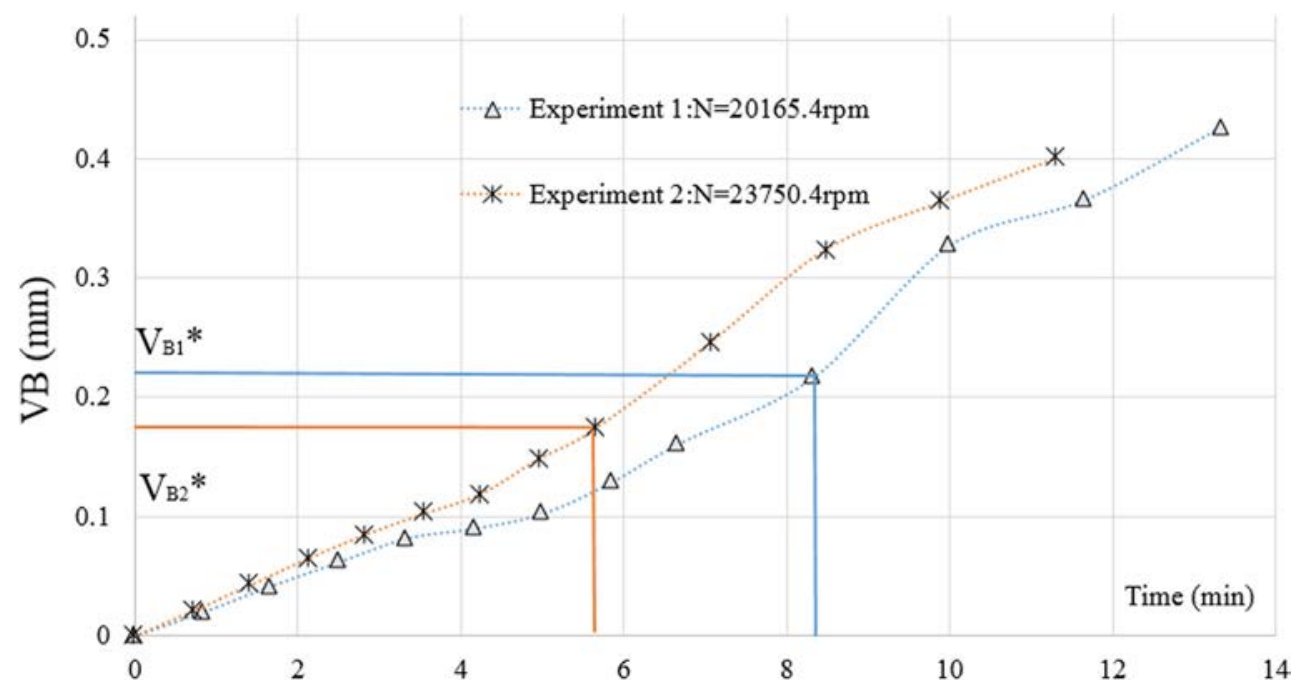

The second constant $c$ is calculated by:

$c=\frac{a \Delta t_{4} N_{41}^{g-d}}{V_{B 4}}\left(1+r^{g-d}+r^{2(g-d)}+r^{3(g-d)}\right)=1.03210^{13}$

- The tool life is so defined according to the spindle speed with this relation:

$T=1.03210^{13} N^{-2.77}$

\subsection{Tool wear results}

The tool life decreases in ball-end milling when increasing the spindle speed. This diminution has a more accurate aspect when using a wear criterion value variable as a function of the spindle speed. The flank wear defined by the wear criterion and the tool life evolution is presented in Fig. 10 according to the models defined previously (Eq. 6). This empirical model was validated by the experimental results of the first and second experiments (Fig. 10). A good agreement was observed between the measured results of experiments 1 and 2 and the predicted results of the Taylorian model using the accelerated wear experiments 3 and 4 .

Figure 11 shows the flank wear evolution according to the time of the accelerated wear experiment conditions presented previously in Table 3.

The evolution of the flank wear for each spindle speed is delimited by the wear criterion value in the flank wear axis and by the tool life in the time axis. The detailed results are presented in Table 4 where it is clear that for both experiments, the tool life and the flank wear criterion decrease according to the rise of the spindle speed.

The accelerated wear experiments presented in the previous section have a main advantage that it is carried out with a large number of parameters when the spindle speed is changed from a level to another for experiments 3 and 4. Therefore, these experiments are conducted under eight spindle speed values. This method replaces the traditional experimental one, which needs the determination of a big number of

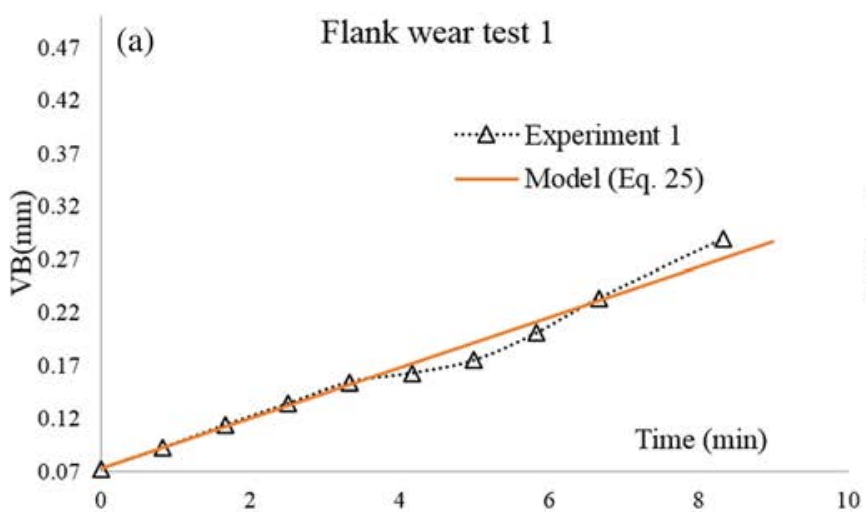

Fig. 10 Experimental and empirical evolution of flank wear. a Experiment 1: $K=0.02363, V_{B}{ }^{*}=0.29 \mathrm{~mm}, N=20,165.4 \mathrm{rpm}$. b

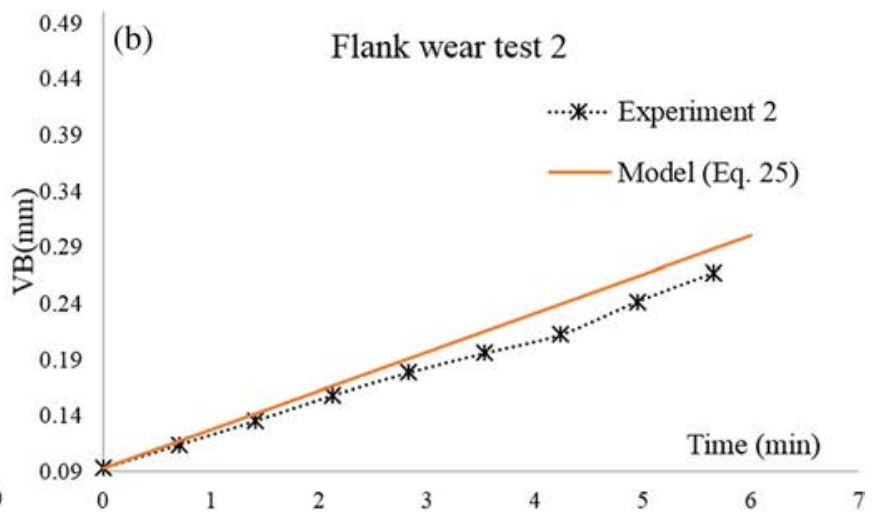

Experiment 2: $K=0.03426, V_{B}{ }^{*}=0.267 \mathrm{~mm}, N=23,750.4 \mathrm{rpm}(f z=$ $0.1 \mathrm{~mm} /$ tooth, $a p=a e=1 \mathrm{~mm}, R_{n 0}=5 \mathrm{~mm}$ ) 
Fig. 11 Empirical evolution of flank wear in each of the accelerated wear experiment conditions $(f z=0.1 \mathrm{~mm} /$ tooth, $a p$ $=a e=1 \mathrm{~mm}, R_{n 0}=5 \mathrm{~mm}$ )

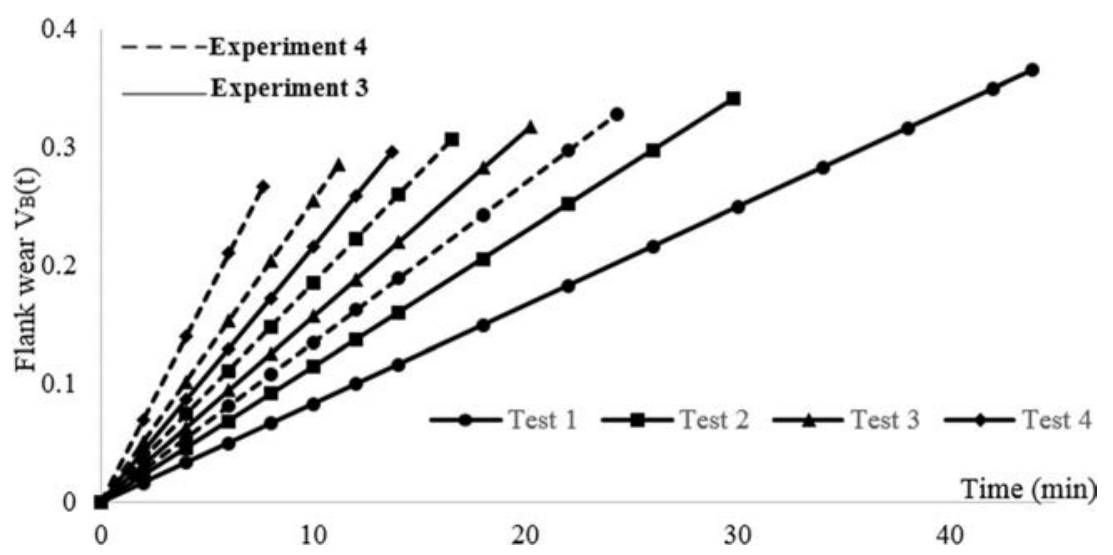

Table 4 Flank wear criterion and tool life results

\begin{tabular}{llllll}
\hline & \multicolumn{2}{l}{ Experiment 3 } & & \multicolumn{2}{l}{ Experiment 4 } \\
\cline { 2 - 3 } \cline { 5 - 6 } & $T(\min )($ Eq. 34) & $V_{B}{ }^{*}(\mathrm{~mm})($ Eq. 23) & & $T(\min )($ Eq. 34) & $V_{B}{ }^{*}(\mathrm{~mm})$ (Eq. 23) \\
\hline Test 1 & 43.9 & 0.36 & 24.32 & 0.32 \\
Test 2 & 29.8 & 0.34 & 16.52 & 0.3 \\
Test 3 & 20.24 & 0.318 & 11.216 & 0.28 \\
Test 4 & 13.74 & 0.29 & 7.615 & 0.26 \\
\hline
\end{tabular}

experimental points to calculate the Taylorian constants through the figure of the tool life.

The evolution of the tool life according to the spindle speed is presented in Fig. 12, knowing that for all our study, we have varied the spindle speed instead of the cutting speed. This is because the spindle speed value is always constant during machining and the cutting speed changes according to the diminution of the tool diameter because of wear.

\subsection{Effect of the wear on the tool and cutting geometry}

The engaged zone of the tool in the workpiece is discretized into a four disks. A geometrical model was developed using the equations of the first section in order to illustrate the effect of the flank wear on the effective radius of the tool for different spindle speeds.

Figure 13 shows the effect of the tool wear on the discretized radius. We choose here to present the evolution of the radius of a medium position $(z=0.5 \mathrm{~mm})$ from the cutting where we measured the tool wear. This will also be considered for all the merged depth of the tool in the workpiece. The increase of the tool wear in time causes the diminution of the effective radius. Therefore, it causes the decrease of the effective cutting speed.

The effective radius reduces for all the chosen spindle speeds where we noticed acceleration in the decrease of this radius according to the spindle speed rise. This is due to the decrease in the tool life and the flank wear criterion value when increasing the spindle speed. Figure 14 shows the evolution of the effective cutting speed as a function of time where it decreases according to the effective radius diminution.

The increase of the wear in time decreases the effective radius of the tool, which causes the modification of the tool geometry. The location angle of the discretized element $\kappa(z, t)$ reduces and the angular position of each increment from tooth tangent in the discretization plane $\varphi(z, t)$ increases as shown in Fig. 15.

On the other hand, the cutting edge inclination angle $\lambda_{s}(z, t)$ rises and the normal rake angle $\gamma_{n}(z, t)$ decreases according to the flank wear augmentation as revealed in Fig. 16.

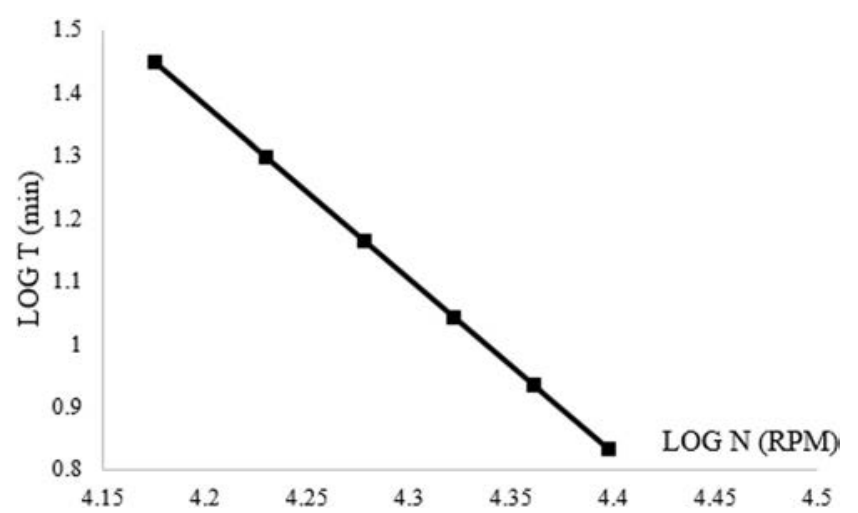

Fig. 12 Evolution of the tool life according to the spindle speed 
Fig. 13 The worn effective radius at $z=0.5 \mathrm{~mm}$ and the wear as a function of time $(f z=0.1 \mathrm{~mm} /$ tooth, $a p=a e=1 \mathrm{~mm}, R_{n 0}=5$ $\mathrm{mm}$ )

Fig. 14 Evolution of the effective cutting speed at $z=0.5 \mathrm{~mm}$ with time $(f z=0.1 \mathrm{~mm} /$ tooth, $a p=a e=$ $1 \mathrm{~mm}, R_{n 0}=5 \mathrm{~mm}$ )

Fig. 15 Evolution of the direction angle of each increment in $P r$ and the angular position of each increment from tooth tangent in $P \mathrm{a}(f z=0.1 \mathrm{~mm} /$ tooth,$a p=a e=1$ $\mathrm{mm}, R_{n 0}=5 \mathrm{~mm}$ )
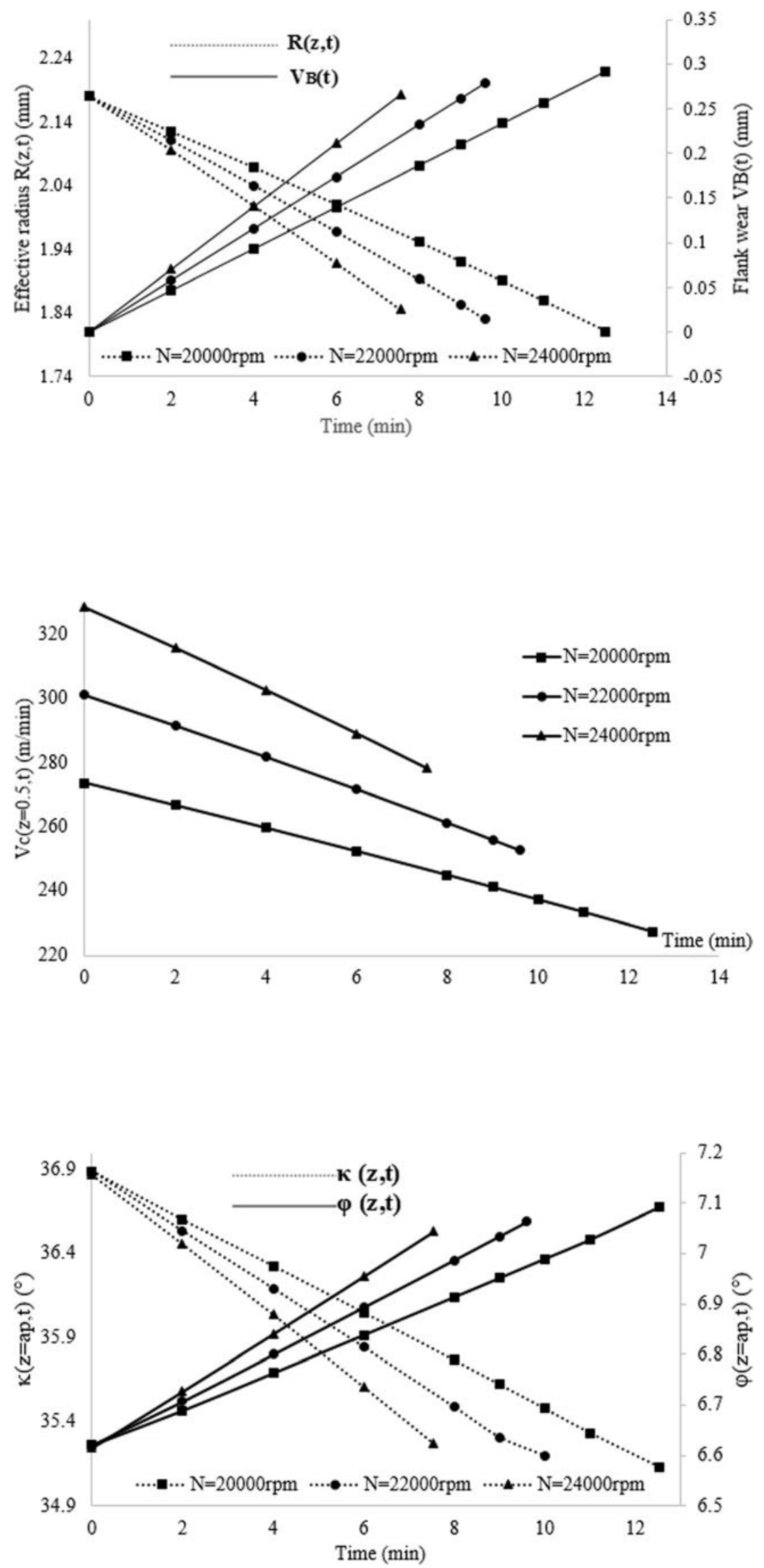


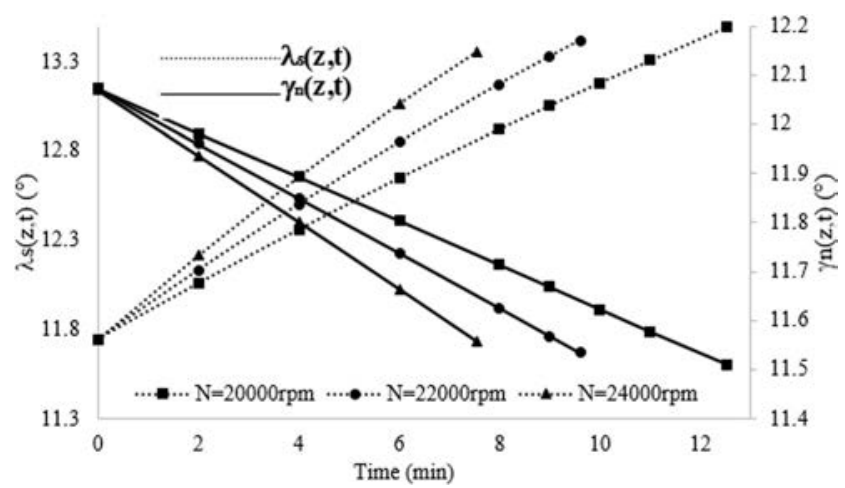

Fig. 16 Evolution of the cutting edge inclination angle and the rake angle $\left(f z=0.1 \mathrm{~mm} /\right.$ tooth $\left., a p=a e=1 \mathrm{~mm}, R_{n 0}=5 \mathrm{~mm}\right)$

As said before, the flank wear has an important effect also on the cutting geometry. The increase of the direction angle of each increment in the reference plane $\kappa(z, t)$ causes both the diminution of the uncut chip thickness and the rise of the chip width. The evolution of the uncut chip thickness according to the cutting time is presented in Fig. 17 where it decreases according to the wear rise. The evolution of the chip width is presented in Fig. 17 where it increases according to the increase of the wear. It is observed that the effect of the flank wear is more important for the chip width compared with the uncut chip thickness.

\section{Conclusion}

In this work, an experimental investigation was carried out in high-speed machining of the AISI 4142. The sintered carbide tool is coated with a TiSiN layer. A tool life model for the used tool is defined using a variable wear criterion model. In highspeed milling, the wear criterion could not have a constant value; therefore, we choose to identify it as a function of the spindle speed. The tool life is defined based on the Taylorian method using the third and the fourth experiments; this empirical model was validated using the evolution of the wear as a function of time basing on the first and the second experiments. The different models are defined as a function of the spindle speed. Following the evolution of the tool wear as a function of time, the real tool radius and the effective cutting speed could be calculated. The results showed an important effect of the tool wear on the tool geometry and on the tool life. A higher spindle speed value decreases the tool life and the wear criterion value. The effective radius of the tool decreases as a function of time, which causes the diminution of the effective cutting speed. For example, for a spindle speed $N$ $=22,000 \mathrm{rpm}$, during the tool life $T=9.611 \mathrm{~min}$, the effective radius decreases for $z=0.5 \mathrm{~mm}$ from 2.179 to $1.82 \mathrm{~mm}$ resulting in the diminution of the effective cutting speed from 301 to $253 \mathrm{~m} / \mathrm{min}$. The cutting edge inclination increases from $11.74^{\circ}$ to $13.42^{\circ}$ and the direction angle of each discretized element decreases from $36.88^{\circ}$ to $35.2^{\circ}$. The tool flank wear has also a significant effect on the cutting geometry where it causes the decrease of the uncut chip thickness and the increase of the cutting width. The ball-end mills used in our experiments display its good behavior in dry high-speed milling of the AISI 4142; this is due principally to the effect of the TiSiN coat despite its existence in a single layer of $2 \mathrm{~mm}$. In future works, we will develop an analytical cutting force model considering the effect of the flank tool wear and we will study the effect of this wear on the topography of the machined surfaces.
Fig. 17 Maximal uncut chip thickness and cutting width of the worn tool for $z=a p$ and $\Delta z=$ $0.25 \mathrm{~mm}(f z=0.1 \mathrm{~mm} /$ tooth, $a p=$ $\left.a e=1 \mathrm{~mm}, R_{n 0}=5 \mathrm{~mm}\right)$

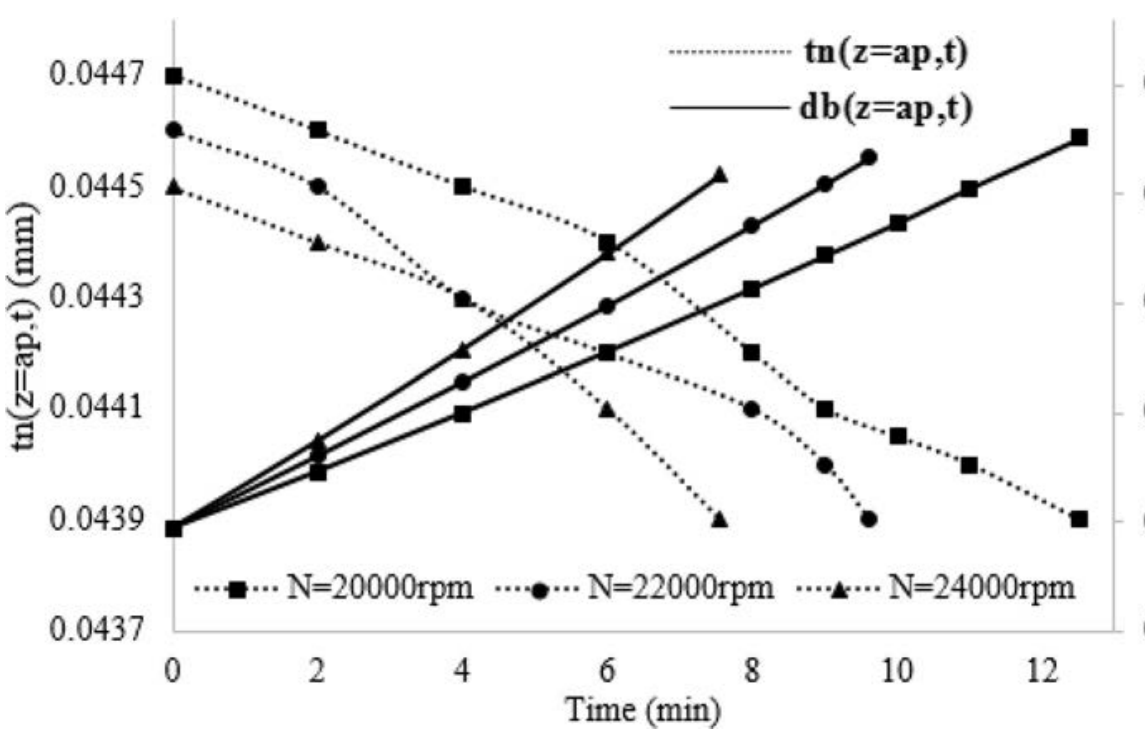

0.437 
Acknowledgments The work is carried out thanks to the support and funding allocated to the Unit of Mechanical and Materials Production Engineering (UGPMM / UR17ES43) by the Tunisian Ministry of Higher Education and Scientific Research.

\section{References}

1. Halila F, Czarnota C, Nouari M (2014) New stochastic wear law to predict the abrasive flank wear and tool life in machining process. Proc Inst Mech Eng Part J J Eng Tribol 228:1243-1251. https://doi. org $/ 10.1177 / 1350650114521405$

2. Sai WB, Zghal A, Ayed KB (2005) Carbide and ceramic tool life in high speed turning. Int J Veh Des 39:140. https://doi.org/10.1504/ IJVD.2005.007225

3. Bouzakis K-D, Skordaris G, Gerardis S, Katirtzoglou G, Makrimallakis S, Pappa M, LilI E, M'Saoubi R (2009) Ambient and elevated temperature properties of TiN, TiAlN and TiSiN PVD films and their impact on the cutting performance of coated carbide tools. Surf Coat Technol 204:1061-1065. https://doi.org/10.1016/j. surfcoat.2009.07.001

4. Wojciechowski S, Twardowski P (2012) Tool life and process dynamics in high speed ball end milling of hardened steel. Procedia CIRP 1:289-294. https://doi.org/10.1016/j.procir.2012.04.052

5. Twardowski P, Legutko S, Krolczyk GM, Hloch S (2015) Investigation of wear and tool life of coated carbide and cubic boron nitride cutting tools in high speed milling. Adv Mech Eng $7: 1687814015590216$. https://doi.org/10.1177/ 1687814015590216

6. Wang CY, Xie YX, Qin Z, Lin HS, Yuan YH, Wang QM (2015) Wear and breakage of TiAlN- and TiSiN-coated carbide tools during high-speed milling of hardened steel. Wear 336-337:29-42. https://doi.org/10.1016/j.wear.2015.04.018

7. Stavropoulos P, Papacharalampopoulos A, Vasiliadis E, Chryssolouris G (2016) Tool wear predictability estimation in milling based on multi-sensorial data. Int J Adv Manuf Technol 82: 509-521. https://doi.org/10.1007/s00170-015-7317-6
8. Yuan Y, Qin Z, Yu D, Wang C, Sui J, Lin H, Wang Q (2017) Relationship of microstructure, mechanical properties and hardened steel cutting performance of TiSiN-based nanocomposite coated tool. J Manuf Process 28:399-409. https://doi.org/10.1016/j. jmapro.2017.07.007

9. Okokpujie IP, Ohunakin OS, Bolu CA, Okokpujie KO (2018) Experimental data-set for prediction of tool wear during turning of Al-1061 alloy by high speed steel cutting tools. Data Brief 18: 1196-1203. https://doi.org/10.1016/j.dib.2018.04.003

10. Chang C-L, Chen W-C, Tsai P-C, Ho W-Y, Wang D-Y (2007) Characteristics and performance of TiSiN/TiAlN multilayers coating synthesized by cathodic arc plasma evaporation. Surf Coat Technol 202:987-992. https://doi.org/10.1016/j.surfcoat.2007.06. 024

11. Cheng YH, Browne T, Heckerman B, Meletis EI (2010) Mechanical and tribological properties of nanocomposite TiSiN coatings. Surf Coat Technol 204:2123-2129. https://doi.org/10. 1016/j.surfcoat.2009.11.034

12. Weicheng K, Hui S, Dejun K (2018) Microstructure and tribological properties of cathodic arc ion plated TiAlN and TiSiN coatings at high temperatures. J Tribol 140:041301-041301-9. https://doi. org/10.1115/1.4039135

13. Ning L, Veldhuis SC (2006) Mechanistic modeling of ball end milling including tool wear. J Manuf Process 8:21-28. https://doi. org/10.1016/S1526-6125(06)70098-6

14. Ben Said M, Saï K, Bouzid Saï W (2009) An investigation of cutting forces in machining with worn ball-end mill. J Mater Process Technol 209:3198-3217. https://doi.org/10.1016/j. jmatprotec.2008.07.028

15. Sai L, Belguith R, Baili M, Dessein G, Bouzid W (2018) An approach to modeling the chip thickness and cutter workpiece engagement region in 3 and 5 axis ball end milling. J Manuf Process 34(Part A):7-17. https://doi.org/10.1016/j.jmapro.2018.05.018 